\title{
A SERPENTE PEDAGÓGICA: O PROJETO ESCOLA SEM PARTIDO E O ENSINO DE SOCIOLOGIA NO BRASIL ${ }^{1}$
}

\section{THE PEDAGOGICAL SERPENT: ABOUT THE NON-PARTY SCHOOL AND THE TEACHING OF SOCIOLOGY IN BRAZIL}

\author{
FERREIRA, Walace ${ }^{2}$ \\ ALVADIA FILHO, Alberto $^{3}$
}

\section{ReSUMO:}

Este trabalho analisa como o programa Escola sem Partido, considerando tanto suas forças enquanto movimento de ordem conservadora quanto suas propostas de lei, podem impactar o ensino e o currículo de Sociologia no Ensino Médio brasileiro. O ESP trata de valores como moral, ética, laicidade e liberdade no âmbito da pluralidade, quando, na verdade, supõe a supressão da pluralidade em favor de um ensino que se pretende estéril e unidimensional, estimulando o denuncismo, o controle e o cultivo a valores nocivos pedagogicamente. A Sociologia, por sua vez, é uma ciência que estabelece formas de estranhamento, propondo a desnaturalização e a problematização das relações sociais, reafirmando sua historicidade e sua materialidade. A partir da perspectiva de que o conteúdo da disciplina será duramente afetado com a implantação do projeto, a proposta deste artigo é abordar estes aspectos de forma crítica, refletindo sobre o presente e o futuro do seu ensino.

Palavras-chave: Escola sem Partido; Ensino de Sociologia; Currículo; Educação; Conservadorismo.

\begin{abstract}
:
This paper analyzes how the Non-Party School Program, considering both its strength as a conservative movement and its legislative proposals, can impact the teaching and the curriculum of Sociology in Brazilian High School. Non-Party School intend to deal with values such as morality, ethics, secularism and freedom in the context of plurality, when, in fact, it supposes the suppression of plurality in favor of a sterile and unidimensional teaching, stimulating denunciation, control and cultivation of values which are pedagogically harmful. Sociology, in turn, is a science that establishes forms of estrangement, proposing the denaturalization and problematization of social relations, reaffirming its historicity and its materiality. From the perspective that the content of the discipline will be hard affected with the implementation of the project, the purpose of this article is to approach these aspects critically, reflecting on the present and the future of its teaching.
\end{abstract}

KeYwORDS: Non Party School; Teaching Sociology; Curriculum; Education; Conservatism.

${ }^{1} \mathrm{O}$ termo "serpente" se refere à metáfora utilizada no filme $\mathrm{O}$ ovo da serpente (1977), de Ingmar Bergman, que retrata um momento que a Alemanha democrática da República de Weimar perde terreno para a escalada do Nazismo.

${ }^{2}$ Professor Adjunto de Sociologia do CAp-UERJ. Doutor em Sociologia (IESP/UERJ). e-mail: walace.ferreira@uerj.br

3 Professor de Sociologia do IFRJ - Campus São João de Meriti; Mestre em Ciências Sociais pelo PPCIS/UERJ. e-mail: alberto.filho@ifrj.edu.br 


\section{INTRODUÇÃO}

A projeção pública de uma organização autodenominada Escola sem Partido (doravante chamado de ESP) exige estudos, reflexões e debates acerca dos danos que sua efetivação legal pode provocar não apenas aos currículos das Ciências Humanas, expressa aqui pelo currículo de Sociologia, mas em todo o projeto pedagógico que se pretenda democrático e emancipatório.

Ao falar do ESP precisamos considerar tanto as forças que constituem o seu movimento quanto as propostas de lei que o representam. Existem inúmeros projetos que tramitam na Câmara, no Senado e em diversas casas legislativas pelo país, de modo que integram um pacote de contrarreformas juntamente com 0 projeto de lei de reforma do Ensino Médio (PL 746/2016) e com a PEC 55/2016 (exPEC 241).

É nesse sentido que o ESP deve ser lido, sob a perspectiva conservadora que se difunde pelo país, fruto de um contexto de acirramento político marcado pelo crescimento de uma vertente autoritária que emergiu nos últimos anos e em especial após o impeachment de 2016.

A episteme por trás do programa retrata a mercadologização definitiva das relações sociais mais primárias, lógica que não poupa sequer a educação dos tentáculos do consumo. O ESP idealiza uma escola reduzida às relações do capital na qual a relação escola-professor-aluno fica restrita ao nexo mercantil.

É nessa conjuntura que pensamos o papel da Sociologia, tanto nos riscos que seu currículo sofre, quanto no papel de defensor de uma escola crítica, democrática, reflexiva e como porta-voz da cidadania e dos direitos humanos.

Estamos diante de uma serpente do autoritarismo cujos ovos já foram chocados e estão em fase de eclosão.

\section{O Escola Sem Partido - movimento, Projetos e incidências Pelo Brasil}

Criado em 2004, o ESP apresenta-se como uma iniciativa conjunta de estudantes e pais preocupados com o que chamaram de "grau de contaminação político-ideológica das escolas brasileiras". A centralidade de suas ações e concepções está num site ${ }^{4}$ que atua com os objetivos de veicular ideias, instrumentalizar denúncias, disseminar procedimentos de vigilância, além de controlar e criminalizar o que seus membros entendem como "práticas doutrinárias" realizadas em salas de aula e presentes em materiais escolares e acadêmicos, livros

\footnotetext{
${ }^{4}$ Disponível em: http://www.programaescolasempartido.org/. Acesso em: 01 de julho de 2017.
} 


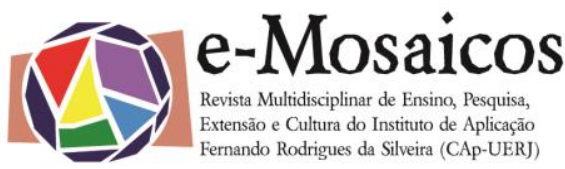

DOI: $10.12957 /$ e-mosaicos.2017.30272

didáticos e programas formativos. O ESP também concentra forças nas redes sociais, tendo no facebook ${ }^{5}$ uma página com os mesmos propósitos.

O fundador do movimento é o advogado e procurador do Estado de São Paulo Miguel Nagib, que se declara publicamente em nome da organização. Nagib, por sua vez, foi articulista e doador do Instituto Millenum (Imil), um dos mais representativos think-thanks do pensamento liberal brasileiro, o que nos revela a orientação ideológica que marca o começo do ESP e que influencia muitas de suas manifestações (ESPINOSA; QUEIROZ, 2017).

É curioso perceber que no site há um rótulo com o nome "ESP nas eleições 2016", onde se podem encontrar políticos apoiadores do movimento. Parece contraditório que um projeto batizado como "sem partido" tenha apoio de políticos, logo, de partidos. Muitos deles, inclusive, têm realizado propostas baseadas no anteprojeto disposto no sítio do $\mathrm{ESP}^{6}$ nas casas legislativas onde atuam. No plano federal há o PL 867/20157, que tramita na câmara, de autoria do deputado Izalci Lucas Ferreira (PSDB/DF); e o PLS 193/2016², que está no Senado, de autoria do senador Magno Malta (PR/ES). Ambos propõem a alteração da LDB $96 \mathrm{com}$ a inserção dos aspectos defendidos pelo programa. Outro projeto de lei, mais severo e que foi retirado em abril de 2017, era o PL $1411 / 2015^{9}$ do deputado federal Rogério Marinho (PSDB/RN), que tipificava o crime de assédio ideológico com pena de prisão aos professores "infratores".

Há uma relação próxima do ESP com a direita brasileira. A proposta foi apresentada pela primeira vez em forma de projeto de lei em 2014, no estado do Rio de Janeiro, pelo deputado Flávio Bolsonaro (PSC/RJ). A segunda vez, ainda nesse ano, foi no município do Rio de Janeiro, pelo vereador Carlos Bolsonaro (PSC/RJ), ambos filhos do deputado federal Jair Bolsonaro (PSC/RJ). Existe também um vínculo do movimento com a bancada evangélica de diversas esferas legislativas, especialmente pelo fato de o programa combater a discussão de gênero e a diversidade religiosa nas escolas. Na câmara federal, por exemplo, a comissão

\footnotetext{
${ }^{5}$ Chamada Escola sem Partido. Disponível em: https://www.facebook.com/escolasempartidooficial/ Acesso em: 21 de julho de 2017.

${ }^{6}$ Existe três anteprojetos no site, bem semelhantes, um federal, outro estadual e o terceiro municipal.

7 Todos os trâmites do projeto, assim como o texto original, podem ser acessados no portal da Câmara Federal. Disponível em: http://www.camara.gov.br/proposicoesWeb/fichadetramitacao? idProposicao=1050668. Acesso em: 01 de julho de 2017.

${ }^{8} \mathrm{O}$ texto do projeto pode ser lido portal do Senado Federal, onde o leitor também pode manifestar a opinião através de um voto. Disponível em: https://www12.senado.leg.br/ecidadania/ visualizacaomateria?id=125666. Acesso em: 01 de julho de 2017.

9 Esse PL entendia como assédio ideológico "toda prática que condicione 0 aluno a adotar determinado posicionamento político, partidário, ideológico ou qualquer tipo de constrangimento causado por outrem ao aluno por adotar posicionamento diverso do seu, independente de quem seja o agente". Disponível em: http://www.camara.gov.br/proposicoesWeb/prop_mostrarintegra? codteor $=1330054$. Acesso em: 01 de julho de 2017.
} 


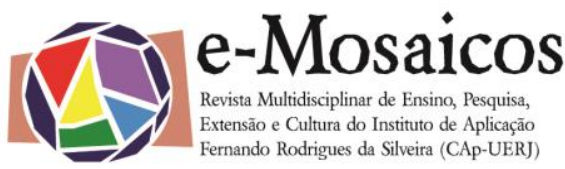

DOI: $10.12957 /$ e-mosaicos.2017.30272

especial que analisa a proposta, criada em 2016, é composta pela bancada evangélica ${ }^{10}$.

O programa chegou a virar lei temporariamente em Alagoas sob o título de "Lei da Escola Livre"11. Em abril de 2017, o ministro Luís Roberto Barroso, do STF, concedeu liminar que a suspendeu na íntegra. Na decisão, Barroso destacou que a lei "é tão vaga e genérica que pode se prestar à finalidade inversa: a imposição ideológica e a perseguição dos que dela divergem. Portanto, a lei impugnada limita direitos e valores protegidos constitucionalmente (...)"(STF NOTÍCIAS, 2017). Com a decisão, o Escola Livre fica invalidado até o julgamento em definitivo pelo pleno do tribunal.

Já em cidades como Campo Grande (MS) e Picuí (PB) o Escola sem Partido foi aprovado, porém vetado após intensos protestos de movimentos de professores. Já em Santa Cruz do Monte Castelo, norte do Paraná, onde o programa virou lei e está em vigor, a rede primária do município passou a ter escolas tomadas por cartazes com os seguintes dizeres: "O professor não pode se aproveitar dos alunos para promover seus próprios interesses ou preferências ideológicas, religiosas, políticas e partidárias"(GOMES, 2016).

Em formato de projeto de lei, o ESP segue sendo debatido em pelo menos 11 estados da federação e dezenas de municípios brasileiros.

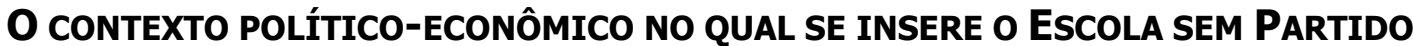

Nenhum movimento social, nem projetos de lei que encampem suas ideias, podem ser dissociados do contexto em que se desenvolvem. É nesse sentido que o ESP deve ser lido à luz da perspectiva conservadora que se difunde pelo Brasil. Como salientado por Frigotto (2017):

As teses do Escola sem Partido não podem ser entendidas nelas mesmas e nem como algo que afeta apenas a escola e os educadores. Pelo contrário, um olhar na perceptiva da historicidade dos fatos e fenômenos, vale dizer, das determinações mais profundas e menos visíveis que os constituem, indica-nos que se trata de algo já sedimentado nas relações sociais (FRIGOTTO, 2017, p. 18).

\footnotetext{
${ }^{10}$ Importante trabalho que mostra o perfil dos defensores do movimento foi realizado por RATIER, Rodrigo. Perguntas e respostas sobre o "Escola sem Partido", 2016.

${ }^{11}$ No texto promulgado, consta a determinação pela neutralidade de professores, prevendo punição a quem manifestar opinião que induza ao pensamento único de alunos em sala de aula. Todavia, a versão aprovada na Assembleia Legislativa alagoana foi parar no Supremo Tribunal Federal (STF) em uma Ação Direta de Inconstitucionalidade (ADIN) movida pela Confederação Nacional dos Trabalhadores em Estabelecimentos de Ensino (Contee). Ao se manifestar, a Advocacia-Geral da União (AGU) classificou o projeto como inconstitucional, alegando que legisla sobre uma área de competência da União, e também porque infringe o artigo 206 da Constituição, que garante a pluralidade de ideias no ambiente de ensino.
} 
O movimento está ligado a uma agenda multifacetada de propostas políticas que impede o acesso da juventude brasileira não apenas a frações do conhecimento, mas ao próprio conhecimento e ao fazer científico, seja pela intenção de incentivar o impedimento formal da abordagem de determinadas questões no âmbito pedagógico, seja pela falta de oferta curricular que privilegia determinados saberes em detrimento de outros.

A proposta de Emenda Constitucional 241, apelidada de "PEC do Teto dos Gastos", que virou lei, acaba com a vinculação obrigatória de recursos para a educação e a saúde pública e inviabiliza o aumento de financiamento educacional necessário para a implementação das metas do Plano Nacional de Educação, lei 13.005, aprovada em junho de $2014^{12}$ após debate público e participação popular. Sendo um instrumento de planejamento orientado à execução e ao aprimoramento de políticas públicas do setor ente 2014 e 2024, a restrição orçamentária representa um imenso obstáculo na sua execução, ainda mais considerando que os recursos atualmente disponíveis para a educação pública já são insuficientes para garantir um padrão de qualidade que cumpra o previsto na legislação e para enfrentar as profundas desigualdades educacionais presentes no país (CARREIRA, 2016).

Há também que considerarmos a proposta de ampliação da terceirização da atividade fim (PL 4330/2004), que, na educação, abrirá caminho para minar ainda mais a carreira docente, o que impactará fortemente na qualidade do serviço prestado à população.

Este combo é um ataque frontal ao ensino no país e tem sua gestação num parlamento cujas propostas têm sido sistematicamente reprovadas pela sociedade e por técnicos. E preciso deixar claro que a agenda com a qual estamos lidando vai de encontro aos interesses dos menos favorecidos social e economicamente e daqueles que fazem da vida um compromisso com estes interesses e com a emancipação societária por meio da educação.

Com efeito, a Reforma do Ensino Médio, sustentada num forte esquema de lobbys e propagandas, pode vir a atingir alguns dos objetivos propostos pelo movimento ESP. Segundo Vieira (2017), isso pode acontecer diante de algumas tendências que estamos assistindo. A primeira delas seria a retirada do peso de matérias que exigem uma abordagem crítico-reflexiva do currículo. A segunda reside no incentivo ao modelo de ensino tecnicista, que compreende a educação como formadora de mão-de-obra massiva, especializada e barata direcionada ao mercado de trabalho. A terceira, e mais dramática, está no reforço da reprodução das desigualdades estruturais que já orientam o modelo educacional brasileiro, uma vez

\footnotetext{
${ }^{12}$ A Lei 13.005 está disponível em: http://www2.camara.leg.br/legin/fed/lei/2014/lei-13005-25-junho2014-778970-publicacaooriginal-144468-pl.html. Acesso em: 19 jul. 2017. Já o Plano Nacional de Educação está disponível em: http://www.observatoriodopne.org.br/uploads/reference/file/439/ documento-referencia.pdf. Acesso em: 19 de julho de 2017.
} 
que a educação espelha as desigualdades sociais do país ao mesmo tempo em que as reproduz.

O contexto em que vivemos suscita o pensamento de Istán Mészáros (2002), que atribui a crise atual a um movimento universal que atinge todas as esferas da vida, além de se tratar de um problema agudo e destrutivo de uma série de direitos. Nesse sistema, cada vez mais irracional, temos assistido a redução da força do poder político dos Estados nacionais e a transferência do governo do mundo para os organismos internacionais.

O ESP aparece no cerne das mudanças culturais que fazem parte desse grande sistema voltado para o lucro. É nesse contexto em que, para os partidários desse programa, a educação responde aos interesses do grande capital sob a aparência cívica do "Todos pela Educação" (FRIGOTTO, 2017).

Como foi bem destacado por Lopes e Siqueira (2017), não é novidade o interesse empresarial na educação brasileira, e em escala mundial, pela própria generalização da lógica do capital. Se essa lógica não é um elemento novo, o nosso estranhamento com o conjunto de políticas educacionais e trabalhistas que vem se generalizando no Brasil se deve à velocidade de perdas de conquistas históricas e avanço de uma lógica conservadora e atrasada no pensamento educacional.

\section{ESCOLA SEM PARTIDO E AS TRÊS FACETAS CENTRAIS DA EDUCAÇÃO: O PROFESSOR, O ALUNO E A RELAÇÃO ENSINO-APRENDIZAGEM}

Os defensores do ESP criticam a escola, os professores, algumas das referências teóricas utilizadas no campo da educação, os livros didáticos e colocam os alunos como vítimas de um processo "doutrinário". Para Fernando Penna (2016), um dos mobilizadores da luta dos professores contra o projeto ${ }^{13}$, esse trabalho de desqualificação não ocorre através de uma argumentação racional, mas por meio de uma série de ataques pessoais e de imagens, muitas delas caricaturas de profundo mau gosto, que representam o professor, a escola e seus pensadores como ameaças a crianças inocentes, mesmo que não haja qualquer dado substantivo que apoie essa generalização indevida. Um exemplo está na imagem abaixo, compartilhada pelo próprio ESP na sua página no Facebook. Nela, um professor, de camisa vermelha e estrela no peito ${ }^{14}$, "enfia pela guela" informações sobre gênero (representada pelo arco-íris - símbolo do movimento LGBT).

\footnotetext{
${ }^{13}$ Existe um grupo no facebook que concentra notícias e mobilizações contra o movimento chamado "Professores contra o Escola sem Partido". Disponível em: https://www.facebook.com/ contraoescolasempartido/. Acesso em 21 de julho de 2017.

${ }^{14}$ Devemos lembrar que o Partido dos Trabalhadores (PT), mesmo não estando mais no governo federal, é, para os membros do ESP, o responsável por grande parte da ideologização presente na educação, sendo seus políticos alvo de manifestações de ódio e ofensas.
} 
e-Mosaicos - Revista Multidisciplinar de Ensino, Pesquisa, Extensão e Cultura do Instituto de Aplicação Fernando Rodrigues da Silveira (CAp-UERJ) V. 6 - N. 12 - AGOSTO 2017 - ISSN: 2316-9303

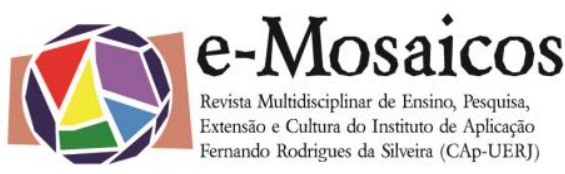

DOI: $10.12957 /$ e-mosaicos.2017.30272

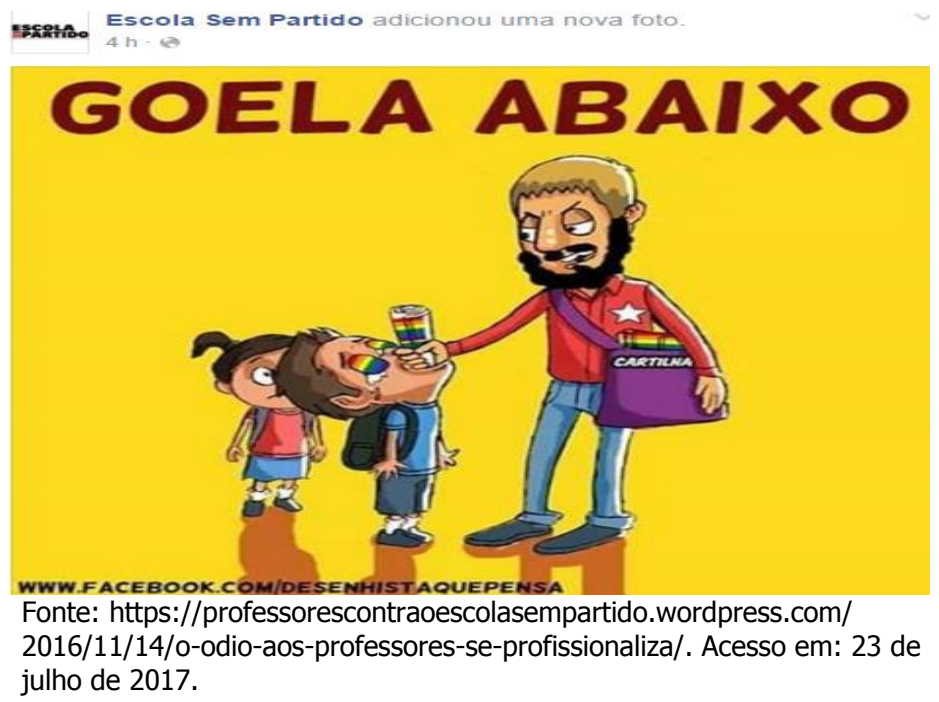

Noutra imagem, postada como um comentário na mesma página, um homem mira uma arma de cano duplo na direção de quem olha. A mensagem ameaçadora demonstra o caráter agressivo do que chamam de "doutrinação" em torno da "ideologia de gênero", entendendo que a escola executa papel único na orientação de gênero do indivíduo, descartando tantas outras forças socializadoras do cotidiano.

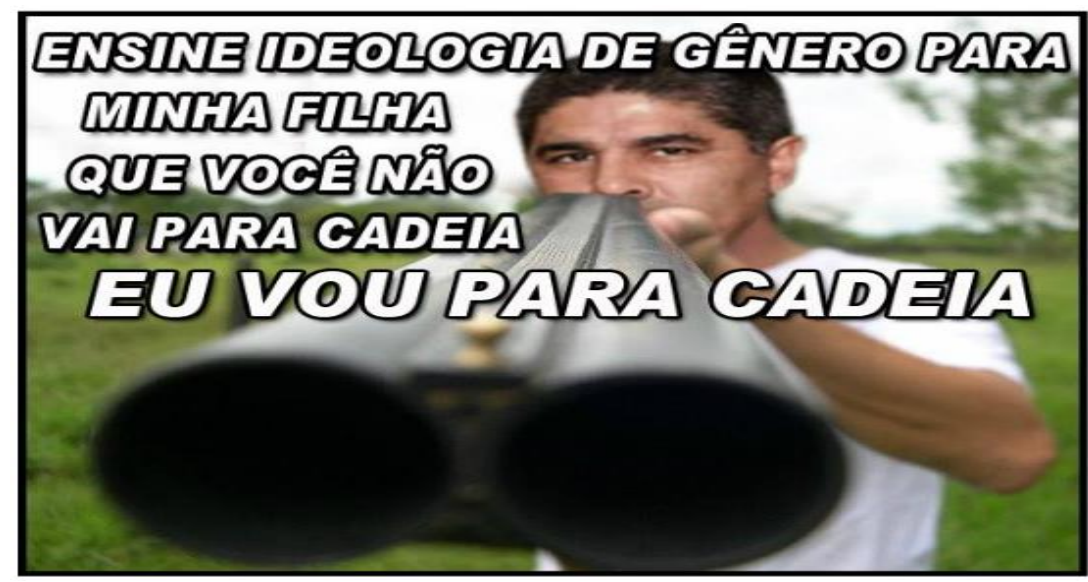

Fonte: https://professorescontraoescolasempartido.wordpress.com/2016/11/14/0odio-aos-professores-se-profissionaliza/. Acesso em: 23 de julho de 2017.

Naquilo que entendem como deveres do professor, seus defensores pregam que as salas de aula dos ensinos fundamental e médio devem ter o seguinte cartaz: 


\section{Deveres do professor}

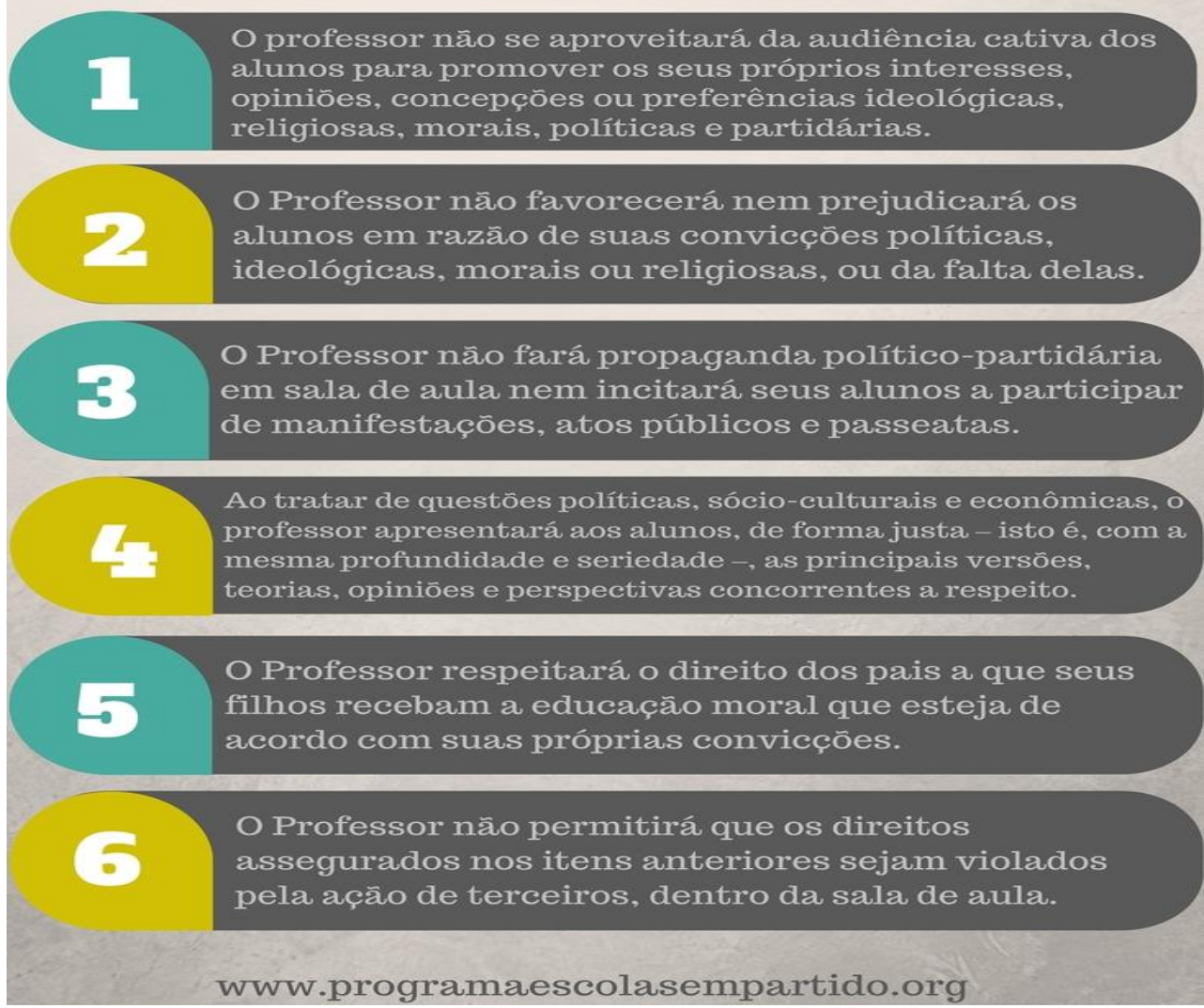

Fonte: www.programaescolasempartido.org

A desconfiança em relação ao educador é um dos pilares do ESP e se traduz numa ameaça constante ao seu trabalho em sala de aula, entendendo-o como um tradutor "perigoso" do conhecimento diante de estudantes supostamente vulneráveis à chamada doutrinação. Vale lembrar que a criação do movimento por Nagib se deu por uma causa pessoal ocorrida no final de 2003. Segundo conta, o impulso ocorreu após sua filha ter dito que o professor de História comparou Che Guevara a São Francisco de Assis demonstrando casos de pessoas que abriram mão de tudo por uma ideologia (EL PAIS, 2016).

Em continuidade à desconfiança com que vê o professor, ao participar de um debate na Globo News (2015), disse:

Nenhum pai é obrigado a confiar em um professor. Nenhum pai. $\mathrm{O}$ professor quando fecha a porta da sala de aula, ele é o dono do espetáculo. Se ele tiver uma boa formação e tiver bons princípios, sorte do aluno, mas e se não tiver? Como saber? Não é verdade? $\mathrm{E}$ há uma infinidade de pessoas que são mal preparadas e que cujos valores - eu nem entro no mérito se são bons ou ruins - mas que não coincidem com os valores da família (NAGIB, 2015). 
Diante dessa visão, o ESP estimula explicitamente o denuncismo, o controle, a insegurança e o cultivo a valores nocivos pedagogicamente que em nada contribuem para a construção de um ambiente saudável, de confiança e diálogo. Trata-se da aposta na instauração de uma ordem por meio de ameaças, da imposição do medo e da fertilização do discurso de ódio. Em vez da harmonia, coesão e produção de conhecimento, instiga alunos e pais ao papel de delatores. Há relatos substantivos de que professores têm sido denunciados e acusados de doutrinação em diversas salas de aula pelo Brasil, inclusive a partir de gravações de áudio e vídeo realizadas durante as aulas por estudantes com aparelhos celulares.

Ao acessar o site do movimento, assim como a página do facebook, ficamos extremamente incomodados ao pensar no tipo de professor imaginado. Afinal, precisamos indagar que profissional de educação não estará pautando sua ação por preceitos morais e éticos. Não é preciso um projeto como este para nortear "eticamente" a atuação destes professores, que estão entre aqueles que mais trabalham e que têm as menores remunerações do mundo ${ }^{15}$, encarando enormes dificuldades para o desempenho digno de suas atividades.

Há professores com orientações subjetivas diversas, afinal todo indivíduo é único em sua formação, constituída a partir de trajetórias, experiências, interpretações e escolhas ímpares. Isto é basilar na existência humana e base da ciência social. Toda expressão acerca de algo é, portanto, ideológica, considerando ideologia como visão de mundo, como manifestação da subjetividade do indivíduo acerca do que lhe cerca. A objetividade, o discurso estéril, puramente instrumental e desconectado do meio social no qual se inscreve é impossível na dimensão humana do ser. Não há nada de nocivo ou pernicioso nisso, pois é justamente das apreensões diferentes acerca da realidade que surge o debate. A dialética simples composta por tese, antítese e síntese estaria condenada por este projeto?

Um professor não entra em uma sala de aula e ministra o conteúdo que melhor Ihe apraz. As escolas seguem um currículo mínimo aprovado pelo Ministério da Educação e as aulas seguem cronogramas com o conteúdo destes currículos. As atividades pré-planejadas não são comícios políticos de recrutamento de militantes como alguns discursos querem fazer parecer.

O programa enxerga o aluno como uma tábula rasa, que chega ao espaço escolar imaculado de qualquer influência da vida social, como se o estudante não tivesse uma vida anterior, exterior e posterior à sua passagem pela escola. O ESP despreza a influência do espaço ocupado pelos meios de comunicação e pelas mídias diversas, hoje a serviço de valores eminentemente competitivos, consumistas e individualistas, com a qual toda a sociedade se relaciona diuturnamente.

\footnotetext{
${ }^{15}$ Pesquisa da OCDE que mostra essa realidade pode ser vista na seguinte matéria: Disponível em: http://g1.globo.com/bom-dia-brasil/noticia/2016/09/professor-no-brasil-ganha-menos-e-trabalhamais-que-os-de-outros-paises.html. Acesso em: 19 de julho de 2017.
} 
Para Miguel Nagib, ademais, os professores estariam usurpando a autoridade moral dos pais, de modo que o movimento adotou como lemas "\#NãoMexamComAsNossasCrianças", "\#MeusFilhosMinhasRegras", reduzindo os alunos quase a uma propriedade familiar (PENNA, 2017). Um exemplo disso aparece num diálogo entre Nagib e representantes do grupo Revoltados On Line, que apoia o ESP:

A segunda prática ilegal que também se disseminou no sistema educacional é a usurpação do direito dos pais dos alunos sobre a sua educação moral, da autoridade moral dos pais sobre os seus filhos. Também a máquina do Estado, o sistema educacional está sendo usado para isso, para afrontar a autoridade moral dos pais dos alunos sobre eles. $\mathrm{E}$ ai, a gente vê, por exemplo, a lei da palmada é uma consequência disso. Tiraram a autoridade dos pais, né, Miguel? Há um ataque frontal à família. (...) Nós já fizemos um slogan: 'Não mexam com as nossas crianças. Meus filhos, minhas regras' (NAGIB, Miguel; REVOLTADOS ON LINE, 2016) ${ }^{16}$.

Ao tocar na relação entre práticas educacionais e determinações definidas pelo Estado somos levados à conclusão de que política e educação não estão dissociadas. Como salientado por Freire (1999), a neutralidade é usada pela ideologia dominante para treinar os alunos para práticas apolíticas, como se a maneira humana de estar no mundo fosse ou pudesse ser uma maneira neutra. A escola se constitui num espaço de formação onde o estudante deve aprender a analisar, comparar, avaliar, decidir, optar e romper. Como Ramos (2017) destacou:

A inseparabilidade (...) se manifesta no fato de o currículo escolar ser alvo de disputa de classes e um processo de seleção cultural e ideológica. O Escola sem Partido é a própria comprovação deste fato. Trata-se de tentar imprimir ao currículo escolar sua ideologia a qual, enunciada como neutra é, na verdade, totalmente comprometida com a classe dominante, pois impede que os interesses dos dominados sejam abordados na escola (RAMOS, 2017, pp. 81-82).

Quem também questionou a ideia de neutralidade pregada pelo ESP foi o Ministério Público Federal, por meio do Procurador Geral da República, Rodrigo Janot. No parecer de inconstitucionalidade do Projeto de Escola Livre, de Alagoas, o chefe do MPF alegou que a lei suprime discursos fundamentais da vida social ao

\footnotetext{
${ }^{16} \mathrm{O}$ vídeo foi gravado no mesmo dia em que o grupo, sem a presença de Nagib, se encontrou com o então Ministro interino da Educação, Mendonça Filho, em 25 de maio de 2016. Disponível em: https://www.youtube.com/watch?v=LpIMeRoMhWA. Acesso em: 19 de julho de 2017.
} 
proibir o docente de introduzir conteúdos que possam estar em conflito com as conviç̧ões morais, religiosas e ideológicas dos estudantes, seus pais e responsáveis:

A atividade de ensino não é via de mão única. Prevendo a lei que o aluno seria a parte vulnerável da relação de ensino, toma o processo de aprendizagem a partir da posição de autoridade exercida pelo professor e o compreende equivocadamente como atividade monológica e hierarquizada. Tomar o estudante como tabula rasa a ser preenchida unilateralmente com o conteúdo exposto pelo docente é rejeitar a dinâmica própria do processo de aprendizagem (BRASIL, 2016).

Além da descaracterização da essência da relação ensino-aprendizagem, esta ganha, para o ESP, tom absolutamente mercadológico. Nagib afirmou, em entrevista numa Audiência Pública no Senado Federal, em setembro de 2016, que o projeto ESP é baseado no Código de Defesa do Consumidor:

O nosso projeto foi inspirado no código de defesa do consumidor. 0 Código de Defesa do Consumidor intervém na relação entre fornecedores e consumidores para proteger a parte mais fraca, que é o consumidor, o tomador dos serviços que são prestados pelos fornecedores. Da mesma maneira, a nossa proposta intervém na relação de ensino-aprendizagem para proteger a parte mais fraca dessa relação que é o estudante, aquele indivíduo vulnerável, que está se desenvolvendo (NAGIB, 2016).

Portanto, uma tentativa de pensar a educação como uma relação de consumo, tirando-Ihe seus valores nobres e reduzindo-a num mero produto negociável no capitalismo (PENNA, 2017).

\section{Escola sem Partido e o papel da Sociologia}

A Sociologia, no ensino básico, tem por objetivo a análise crítica das relações sociais, despertando no aluno a "imaginação sociológica" descrita pelo sociólogo norte-americano Wright Mills (1975), propondo o uso da disciplina como forma de entender o indivíduo e suas ações perante as estruturas sociais. A primeira conquista da imaginação sociológica é o entendimento de que os seres humanos só podem compreender sua existência e analisar seu futuro percebendo-se parte de um determinado contexto, de modo que nossas ações influenciam e são influenciadas pela dinâmica social. 
O exercício de "transformar o exótico em familiar e o familiar em exótico" proposto pelo antropólogo Roberto Da Matta (1987) é um caminho eficiente para despertar a imaginação sociológica, o que significa problematizar o que é cotidiano, reafirmando sua historicidade, e, portanto, sua materialidade. Desse modo, conforme disposto nas Orientações Curriculares de Sociologia (2006), só é possível tomar certos fenômenos como objeto da disciplina na medida em que sejam submetidos a um processo de estranhamento e desnaturalização, demonstrando que os fenômenos de ordem social não passam de construções ligadas à história e às relações de força presentes nas dinâmicas sociais.

O ESP censura a liberdade de pensamento e a reflexão crítica, itens caros ao currículo da Sociologia. Em decorrência, alveja os direitos civis e, portanto, o exercício pleno da cidadania, já que esta é afetada pela criminalização do estímulo ao exercício dos direitos políticos. Também atinge os Direitos Humanos, já que, por exemplo, condena o debate sobre gênero, desconsiderando a realidade brasileira marcada pela misoginia e por altos índices de violência contra a mulher. Por fim, coloca sob ameaça o professor que abordar a participação política em atos públicos ou em movimentos estudantis ${ }^{17}$. Como alertado por Gadotti (2016):

Estamos diante de uma iniciativa que visa a retirar da escola seu papel essencial de formar para a democracia, o que demonstra 0 caráter autoritário deste movimento. Com isso, quer-se evitar que as crianças possam tomar a palavra. Querem construir uma escola de egoísmos, de individualismo, de competitividade insolidária, que são os valores do capitalismo selvagem que defendem. Competir em vez de compartilhar (GADOTTI, 2016, p. 156).

Por sua vez, Carreira (2016) destacou que as propostas do ESP constituem um ataque ao princípio da pluralidade de ideias na educação, já que defendem a aprovação de leis que vetam discussões fundamentais para a promoção da igualdade na sociedade brasileira:

Questões como as que tratam das discriminações e violências sofridas pelas mulheres, da violência contra a população LGBT (Lésbicas, Gays, Bissexuais, Travestis e Transgêneros), do extermínio de jovens negros por forças policiais, entre outros assuntos que se referem às desigualdades de gênero, raça, sexualidade e a outras

${ }^{17}$ Como tratar em aula, por exemplo, das mobilizações políticas recentes do país e das revoluções históricas mundiais sem ser confundido com alguém que apoia a organização dos jovens diante da política, o que já é extremamente questionável? A linha tênue entre a abordagem e a doutrinação somada com a subjetividade analítica sobre o que é uma coisa ou outra podem fazer com que professores se calem diante de temáticas urgentes ou até mesmo retirem esses temas fundamentais dos currículos por medo de denúncia. 
questões de direitos humanos. Então, por que o ESP defende essas posições? Porque ele é composto por grupos e pessoas que são contrárias ao enfrentamento das profundas desigualdades no Brasil. São contrários ao cumprimento da Constituição Brasileira e da legislação educacional no país. São contrários à noção de que a educação de qualidade é um direito humano de todas as pessoas e não somente de uma parcela da sociedade (CARREIRA, 2016, p. 127128).

Ao inviabilizar questões, o ESP aliena os estudantes de exercitarem a reflexão crítica sobre a realidade com vistas a transformá-la. Alimenta a ideia de que a função da escola pública é silenciar sobre os conflitos sociais, estimulando a acomodação e o individualismo, respondendo somente às demandas instrumentais do mercado de trabalho. A este respeito, Frei Betto (2016) conclui:

Enfim, é a velha artimanha da direita: já que não convém mudar a realidade, pode-se acobertá-la com palavras. E que não se saiba que desigualdade social decorre da opressão sistêmica; a riqueza, do empobrecimento alheio; a homofobia, do machismo exacerbado; a leitura fundamentalista da Bíblia da miopia que lê o texto fora do contexto (BETTO, 2016, p. 67).

Com a reforma do Ensino Médio, além da Sociologia, outras disciplinas com viés distante da ótica do mercado serão prejudicadas. Embora, no artigo $36 \S 5^{\circ}$, a proposta de reforma afirme que: "os currículos do ensino médio deverão considerar a formação integral do aluno, de maneira a adotar um trabalho voltado para a construção de seu projeto de vida e para a sua formação nos aspectos cognitivos e socioemocionais", a lei aglutina História, Geografia, Sociologia e Filosofia sob um guarda chuva denominado Ciências Humanas. Isto desregulamentará o controle sobre os conteúdos, pois confere autonomia aos sistemas de ensino para definir a organização das áreas de conhecimento, as competências, habilidades e expectativas de aprendizagem definidas na Base Nacional Comum Curricular (BNCC) - que, por sua vez, ainda está em desenvolvimento.

Deve-se debater amplamente com a sociedade a implantação de medidas que irão recortar saberes formais para o indivíduo numa idade ainda menor do que a atual, já que, com a nova proposta, será possível optar por uma determinada linha de formação já durante o Ensino Médio. É importante garantir ao ser humano uma formação integral, mas que ultrapasse a medida meramente temporal e avance para a acepção holística do termo, conferindo ao indivíduo do século XXI uma formação multidimensional, cidadã e conectada com os desafios do nosso tempo. A Sociologia, assim como as demais Ciências Humanas, se inscreve nesta perspectiva e tem papel central neste processo. Se a escola não 
DOI: $10.12957 / \mathrm{e}-m o s a i c o s .2017 .30272$

trabalhar com a diversidade e pluralidade de ideias, censurando educadores e educandos, aí sim a instituição escolar estará objetivando a doutrinação ideológica.

\section{CONSIDERAÇõES FINAIS}

Urge refletirmos acerca da base real sobre a qual este projeto se levanta. Se existe mesmo algum tipo de doutrinação nas escolas que tenha uma perspectiva marxista, revolucionária ou subversiva (isto para nos valermos de lugares comuns utilizados pelos advogados do projeto, que remontam os tempos de estado de exceção vividos no país entre 1964 e 1985), qual é a capacidade real que esta suposta doutrinação tem tido de atingir seus objetivos, que justifique um projeto contundente da envergadura do ESP? Qual o percentual de egressos do Ensino Médio filiados a sindicatos, partidos políticos ou militando em organizações políticas? Onde estão estas pessoas que os organizadores de atos públicos não atingem seus objetivos de ocupar ruas ou grandes praças, exceto em atos unificados que congreguem várias categorias? Ao contrário, em geral, as adesões a greves convocadas pelos sindicatos são baixíssimas.

Talvez a energia mobilizada pelos partidários do ESP servisse melhor à sociedade se fosse canalizada para exigir uma educação de qualidade, pautada por um caráter público, gratuito, com estruturas adequadas a alunos e professores, salários dignos para todos os trabalhadores de estabelecimentos educacionais, oferta de alimentação balanceada, acesso a tecnologia de ponta e segurança.

A escola deve cultivar o compromisso com a ciência e com o desenvolvimento da técnica articulada com uma visão crítica de mundo, independente e laica, que respeite os Direitos Humanos, que contribua para a emancipação das minorias e que produza cidadãos conscientes e comprometidos com o bem estar comum. Uma educação que seja aliada do Homem comum e não sua adversária.

A escola tem um papel fundamental na sociedade, o de lidar com o projeto de mundo que será edificada para o porvir. O que se debate nas escolas tem correlação direta com o debate público e com a maneira como os indivíduos se relacionarão com a realidade. Um indivíduo dotado de habilidades e competências para manejar os preceitos da democracia e da cidadania transita melhor em ambientes marcados pela diversidade, contribuindo de forma determinante para a afirmação e para a ampliação de direitos.

Ainda que o projeto ESP não seja aprovado e seja definitivamente considerado inconstitucional, estando, portanto, impedido de se realizar formalmente dentro marcos da legalidade, é imprescindível atentarmos para o conjunto de valores que ele representa. Trata-se de enxergá-lo como a expressão de um campo conservador que assalta a sociedade e pretende transformá-la num celeiro monocromático de intolerância e autoritarismo. Sua força reside muito mais no que representa simbolicamente do que naquilo que terá capacidade de se converter formalmente. 


\section{REFERÊNCIAS BIBLIOGRÁFICAS}

BETTO, Frei. "Escola sem Partido"? In: A ideologia do movimento Escola Sem Partido: 20 autores desmontam o discurso. Ação Educativa Assessoria, Pesquisa e Informação (Org.). São Paulo: Ação Educativa, 2016.

BRASIL. Ministério Público Federal. Parecer na Ação Direta de Inconstitucionalidade 5580. Disponível em: http://www.mpf.mp.br/pgr/documentos/adi-5580-e-adi-5537escola-livre.pdf. Acesso em: 23 de julho de 2017.

CARREIRA, Denise. No chão da escola: Conversando com famílias e profissionais da educação sobre o Escola sem Partido. In: A ideologia do movimento Escola Sem Partido: 20 autores desmontam o discurso. Ação Educativa Assessoria, Pesquisa e Informação (Org.). São Paulo: Ação Educativa, 2016.

DAMATTA, Roberto. Relativizando: uma introdução à antropologia social. Rio de Janeiro: Editora Rocco, 1987.

EL PAIS. O professor da minha filha comparou Che Guevara a São Francisco de Assis. Publicado em 26 de junho de 2016. São Paulo. Disponível em: https://brasil.elpais.com/brasil/2016/06/23/politica/1466654550_367696.html. Acesso em: 18 de julho de 2017.

ESPINOSA, Betty R. Solano; QUEIROZ, Felipe B. Campanuci. Breve análise sobe as redes do Escola sem Partido. In: FRIGOTTO, Gaudêncio (Org.). Escola "sem" partido: esfinge que ameaça a educação e a sociedade brasileira. Rio de Janeiro: UERJ, LPP, 2017.

FREIRE, Paulo. Pedagogia do oprimido. Rio de Janeiro: Paz e Terra, 1999.

FRIGOTTO, Gaudêncio. A gênese das teses do Escola sem Partido: esfinge e ovo de serpente que ameaçam a sociedade e a educação. In: FRIGOTTO, Gaudêncio (Org.). Escola "sem" partido: esfinge que ameaça a educação e a sociedade brasileira. Rio de Janeiro: UERJ, LPP, 2017.

GADOTTI, Moacir. A escola cidadã frente ao "Escola sem Partido". In: A ideologia do movimento Escola Sem Partido: 20 autores desmontam o discurso. Ação Educativa Assessoria, Pesquisa e Informação (Org.). São Paulo: Ação Educativa, 2016.

GOMES, Karina. O único município que adotou o "Escola sem Partido". In: Portal DW. Publicado em 08/09/2016. Disponível em: http://www.dw.com/pt-br/o$\%$ C3\%BAnico-munic\%C3\%ADpio-que-adotou-o-escola-sem-partido/a-19500841. Acesso em: 22 de julho de 2017. 
DOI: $10.12957 /$ e-mosaicos.2017.30272

LOPES, Frederico Alves; SIQUEIRA, Camila Zucon Ramos. Escola em Disputa: educação libertadora ou educação conservadora? In: Anais do VIII Seminário Nacional de Sociologia \& Política. 17, 18 e 19 de maio de 2017, UFPR, Curitiba/PR. Disponível em: <http://e-democracia.com.br/sociologia/anais_2017/pdf/GT0938.pdf>. Acesso em: 20 jul. 2017.

MÉSZÁROS, István. Para além do capital. São Paulo: Boitempo, 2002.

MILLS, Wright. A Imaginação Sociológica. Rio de Janeiro: Zahar, 1975.

NAGIB, Miguel. Entre Aspas (Mônica Waldvogel) Debate sobre sexualidade na grade de ensino escola. Publicado em 11 de junho de 2015. Disponível em:

https://www.youtube.com/watch?v=iNSC1rNOz74. Acesso em: 27 de abril de 2017.

NAGIB, Miguel. Audiência Pública para debater a liberdade de expressão na sala de aula. Publicado em 01 de setembro de 2016. Disponível em:

https://www.youtube.com/watch?v=jwGErV-1zUo. Acesso em: 23 jul. 2017.

MINISTÉRIO DA EDUCAÇÃO. Orientações Curriculares para o Ensino Médio. Vol.3 (Parte de Sociologia). Ciências humanas e suas tecnologias/Secretaria de Educação Básica. Brasília: Ministério da Educação, Secretaria de Educação Básica, 2006.

PENNA, Fernando de Araujo. O Escola sem Partido como chave de leitura do fenômeno educacional. In: FRIGOTTO, Gaudêncio (Org.). Escola "sem" partido: esfinge que ameaça a educação e a sociedade brasileira. Rio de Janeiro: UERJ, LPP, 2017.

PENNA, Fernando de Araujo. O Ódio aos Professores. Publicado por PROFESSORESCONTRAOESP. 14 de novembro de 2016. Disponível em: https://professorescontraoescolasempartido.wordpress.com/2016/11/14/o-odio-aosprofessores-se-profissionaliza/. Acesso em: 20 de julho de 2017.

RAMOS, Marise Nogueira. Escola sem Parido: a criminalização do trabalho pedagógico. In: FRIGOTTO, Gaudêncio (Org.). Escola "sem" partido: esfinge que ameaça a educação e a sociedade brasileira. Rio de Janeiro: UERJ, LPP, 2017.

RATIER, Rodrigo. Perguntas e respostas sobre o "Escola sem Partido". In: $A$ ideologia do movimento Escola Sem Partido: 20 autores desmontam o discurso. Ação Educativa Assessoria, Pesquisa e Informação (Org.). São Paulo: Ação Educativa, 2016.

STF NOTÍCIAS. Suspensa lei alagoana que instituiu o programa Escola Livre. Publicado em 22 de março de 2017. Disponível em:http://www.stf.jus.br/portal/cms/ verNoticiaDetalhe.asp?idConteudo $=338884 \&$ caixaBusca $=N$. Acesso em: 19 de julho de 2017. 
VIEIRA, Rafael Barros. Para uma crítica do Projeto de Lei 193/2016, que inclui na LDB o Programa 'Escola sem Partido'. In: Junho Blog. Publicado em 01 de abril de 2017. Disponível em: http://blogjunho.com.br/para-uma-critica-do-projeto-de-lei1932016-que-inclui-na-ldb-o-programa-escola-sem-partido/. Acesso em: 20 de julho de 2017. 